\title{
ESL Students and American Libraries
}

\section{Gina Macdonald and Elizabeth Sarkodie-Mensah}

The number of students taking English as a Second Language (ESL), attending American colleges, and using American libraries is growing rapidly. Because these students represent various cultures in which English is not the native tongue and because their past library experiences differ considerably from those of American students, ESL instructors and library personnel must consider the best way to communicate effectively with them. Too often American library professionals have difficulty "code-switching" in order to accommodate the students' needs and resort to familiar but ineffective patterns. Analogy, universal humor, handson experience, and an integrated program involving ESL and library personnel can effectively cope with the difficulties and differences, making library use easier and more pleasant.

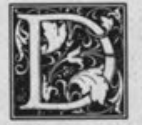

uring the $1983-84$ academic year, nearly 339,000 foreign students were enrolled in American institutions of higher learning. This represents an increase of nearly 200 percent over the 125,000 enrolled just ten years earlier and, up to that time, the largest number ever enrolled in the United States in any single year. ${ }^{1}$ More than 60 percent of these students come from countries where English is neither a second/official language nor a medium of instruction in educational institutions. For these students, learning English is only the first step in the process of achieving the educational goals that brought them to America.

In the attempt to help ESL students attain technical language proficiency, it is all too easy to forget that the skills required for success in college involve far more than that. While these students struggle to master the intricacies and inconsistencies of basic English, they often do not anticipate the even greater difficulties they may later encounter when trying to compre- hend fast-moving lectures, take notes, do research, and write papers in a language that is alien, not only linguistically but also culturally. ${ }^{2}$

American educators have responded to the special needs of ESL students by providing support through offices and programs, international student advisers, and specialized language classes, particularly on campuses where more than 5 percent of the student body is foreign. Historically, however, libraries and librarians have not been directly involved in the cultural and educational adjustment process of the foreign student. Although almost every academic library provides some formal or informal bibliographic instruction, foreign students have benefited littlemainly because librarians have failed to perceive and respond to their unique circumstances. It is encouraging, however, that a scattering of articles on the problem has appeared in library journals over the past several years, indicating that new interest has been generated in teaching library skills to foreign students. ${ }^{3}$ These ar-

Gina Macdonald is Assistant Professor, English, and Elizabeth Sarkodie-Mensah is Bibliographic Instruction Librarian at Loyola University of the South, New Orleans, Louisiana 70118. 
ticles suggest that academic librarians, especially those involved in bibliographic instruction, are finally waking to the unique problems faced by foreign students and beginning to join international student advisers and ESL teachers in responding to the special needs of this growing group. It is the purpose of this paper to encourage that awakening.

Most teachers, and certainly all librarians, would agree that a good grasp of library and research skills would benefit all students. Too often, however, it is assumed that most college freshmen arrive with those skills or will, of necessity, quickly learn them on their own. For the ESL student, learning such skills alone is difficult; for many, it may be impossible. Yet, for these students, such skills are an academic necessity - a matter of classroom survival.

An introduction to an American college library and its services can be particularly valuable, especially for advanced students who are often lulled by high scores on grammar tests into expectations of easy success in college, only to be thwarted by complex research projects and papers. Precollege or first-year preparation in library use and research methods can make all the difference in students' academic success or failure. It is up to American teachers and librarians to help them surmount a hurdle whose existence they might not even realize until it is almost too late.

Cultural differences account for the special library needs of foreign students. In many countries, the predominant teaching method is lecture and recitation; students learn from rote memory and are expected to recall information rather than analyze, synthesize, critique, or expand on it. This is true even in such fields as law, where the Socratic method of argumentative dialogue is standard in our culture. ${ }^{4}$ Thus, students may expect their role to be basically passive, since they have not been trained for active participation. In order to participate actively in learning, one should have a strong background in the subject area. This is acquired by knowing where to go to get information to support one's intuitions, where to find hard facts, and how to marshal them as evidence. Many American college assignments involve forming hypotheses, gathering specialized information to develop and support them, and, in effect, arguing a position rhetorically.

\section{"The very conception of using books and research materials may be quite different in another culture."}

American libraries, like American college classes, may differ significantly from those in ESL students' native cultures. Some have never been exposed to a library as Americans know it. The quantity of books available, the complexity of indexes and catalogs for tracking down information, the multiplicity of automated tools at one's command, and the basic organizational patterns themselves may be bewildering and, perhaps at times, overwhelming and frightening. The very conception of using books and research materials may be quite different in another culture, especially one that, because of its scarcity or a varying attitude toward literacy, regards written materials as special, to be protected at all costs from the depredations of adolescents. Open stacks are far from universal, even in the United States, but abroad the concept may be especially alien.

An extreme case is recounted by Rosalind Pearson in "An American Teaching in Afghanistan." The Peace Corps teacher repeatedly badgers the "keeper of the books" to unlock the storeroom where texts are kept for a seventh-grade class. ${ }^{5}$ The keeper, an uneducated and perhaps illiterate government functionary, steadfastly refuses on the grounds that the students will promptly lose, deface, dirty, or even sell the books, and no more are available. Warehousing the texts and allowing the students and teachers to fend for themselves protects the reputation of the school as being well equipped. The story is, of course, atypical, but it captures attitudes not unknown in the "first world" and not at all unusual in students from the Third World. 
Even students familiar with the concept of library may feel alienated from the actual practice of using it on a daily basis, except as a quiet place to study. Those at the graduate level, accustomed to library work in their own culture, may still have no idea about how American libraries are organized, how to find information amid the unfamiliar stacks, and what variety of services and information is available. Often they will be initially overwhelmed by the immensity of the typical American college library, will have no idea how to begin using it, and may give up without trying. As Kwasi Sarkodie-Mensah points out in "In the Words of a Foreigner," "To many foreign students, the library is only for silent reading. . . . Sometimes it is not easy for foreign students to realize that certain types of ignorance are acceptable, and that librarians are there to help. ${ }^{\prime \prime}$ But those students who persistently pursue their newfound freedom to use materials can end up extolling the virtues of the American library system, marveling at the quantity, quality, and variety of sources available, and becoming library aficionados, who are praised by their professors for the quality of their work.

Commendable efforts to meet the needs of this special group often do not succeed. Many librarians, equipped with good intentions, plenty of enthusiasm, and a whole set of erroneous assumptions, initiate programs for international students with little or no understanding of cultural and linguistic gaps. They may be beguiled by student smiles and nods ${ }^{7}$ or, realizing changes must be made, be unsure how to make them. A student response that would be clear assent from an American student may be mere politeness in a foreign student (as in the Cambodian custom of giving the expected answer the first two times asked, and then the real answer, hesitantly, the third time). ${ }^{8}$ The result of such misunderstandings might lead to bibliographic instruction programs that frustrate both librarian and students. Moreover, those students brave enough to attempt to deal with library personnel and to make use of the kind offers of assistance still face communication problems. 9 In order to devise more successful teaching strategies, librarians and teachers must understand more clearly the backgrounds, abilities, and expectations of the foreign students.

Erroneous assumptions due in part to language difficulties may undermine librarians' most zealous efforts to teach foreign students library skills. One scenario is the "ostrich" approach, simply to hide one's head and ignore the problem. This librarian (or teacher), while perhaps aware that something is not quite right, nonetheless assumes that the foreign students have the same level and speed of comprehension as American students. Hence, in conducting the bibliographic instruction lecture or orientation tour, he or she uses such library jargon as card catalog, indexes and abstracts, periodicals, and citations without explanation. One must remember that even for American students such unexplained terms can be daunting. How much more intimidating will this be for students from completely different linguistic backgrounds, Arabic or Korean, for example? The students may nod politely and one or two may ask intelligent questions, but the majority will leave the session more confused than when they started, or, even worse, determined never again to ask a librarian a question.

Another approach, the "deaf and dumb" strategy, is for the lecturer to speak more loudly, as if volume alone could enhance clarity, and to ignore student responses, thus avoiding the difficulty of determining what they are not understanding. This error also involves speaking unnaturally slowly, breaking each word into syllables, and mouthing the sounds as if to assist lip-reading. Student response will be complete incomprehension of such peculiar behavior, embarrassment for the librarian (especially if other people are listening in), and a desire to escape as quickly as possible. Politeness would prevent complaints, but the students would simply not return.

Related to this error is the "baby talk" approach, condescending to the students by using oversimplified vocabulary and, most deadly, equating pronunciation and speaking difficulties and a limited sense of English word order with limited intelli- 
gence or understanding. In reality, behind the hesitancy might lurk, for example, a university professor of chemistry from Saigon or a successful Brazilian economist. This is precisely the problem. Often ESL students are a little older and more mature than the average college freshmen to whom similar introductions would be made; they have chosen to travel to a distant country in order to further their education and their self-development; they have, in doing so, made emotional and financial sacrifices; they have accepted responsibility for themselves. Some are already recognized professionals in their own country; others, though beginners, are highly motivated. The person who chooses the "baby-talk" approach will often realize, to his own discomfort, that the level of intelligence of his listeners is higher than his approach implies. He may even compound the error by, amid the over-simplified diction, tossing out unexplained technical vocabulary that will confuse the students. Both extremes will fail. Clearly what is needed instead is a balance: recognition of the foreign student's potential to comprehend the technical materials given adequate explanation of terminology, and also clear but interesting, not insultingly simple and condescending language.

\section{"People unaccustomed to addressing non-English speakers often fall back on their previous code-switching ex- perience, with results that can be pa- tronizing or worse, for college-level ESL students are neither childlike nor poorly educated."}

The above situations require what linguists term code-switching, the adjustment of language to accommodate the needs of a listener. We all code-switch naturally when we address children, for example; we consciously or unconsciously codeswitch when we perceive our listeners to have little education, or little understanding of a technical subject. Reference librarians called upon to conduct library tours for high school or elementary school children invariably shift intellectual perspective and mode of presentation to fit their audience; in the same way, they must learn to shift to meet the special perspectives and needs of international students. The problem is that people unaccustomed to addressing non-English speakers often fall back on their previous code-switching experience, with results that can be patronizing or worse, for college-level ESL students are neither childlike nor poorly educated. Such erroneous code-switching is often the result of misinterpretations of linguistic and cultural behavior.

Proficient code-switching can be learned, however, and is the tool of the trade for all ESL teachers and other international student services professionals. The elements of the appropriate code (really a functional variety of English) are quite simple and obvious: repetition abounds; no particular words are automatically taboo, but common sense and experience help eliminate items that are not frequently found in the ESL student's vocabulary (taboo, for example, is a taboo word); technical words that should be mastered are defined in a carefully controlled vocabulary; all slang is avoided; there is a distinct preference for the AngloSaxon over the Latinate; rate of speech is slowed down and articulation enhanced but not to the point of exaggeration. This code is self-taught, based on a constant self-awareness of language when addressing foreign students and from trial and error with different groups.

Cultural differences may prove just as much a barrier as language difficulties, and sometimes the two may overlap. Typical is the case of an ESL teacher, anxious to introduce her students to the library, but wary of trying to explain what she assumed librarians would know so much better. The reference department, in an attempt to bridge the cultural and linguistic gap, selected a staff member of foreign extraction, who had lived in the U.S. since early childhood. In other words, despite a foreign sounding name, he was as American as any other staff member, and encountered the same difficulties they would all have encountered, resulting 
from erroneous assumptions about ESL students.

One grave error that is directly related to the language problem is the assumption that jokes and allusions are international. The librarian mentioned above was experienced in dealing with American college freshmen who were undecided about their futures and very much involved in the American teenage scene. As a consequence, he attempted the same jokes and allusions as before; however, what would suit American teenagers can be either incomprehensible or insulting to the ESL student. Humor differs widely from culture to culture. Consequently, it should not be attempted except at the most basic level, and even then with caution and with an awareness that, if a joke falls flat, one should move quickly on and not compound the problem by attempting explanations.

The impulse to use jokes derives from a recognition that laughter can bridge differences and enliven a potentially dull presentation. A comparison of jokes in different American magazines will illuminate the problem. What is comic to a reader of Playboy will disturb the audience of Reader's Digest; a New Yorker joke will not seem funny in the hills of South Dakota. Jokes that depend on local values and local knowledge simply will not be understood by ESL students, but jokes that have broad human appeal, that build on exaggeration or on universal qualities of human nature, may be effective. Such humor should work at a simple level, as in the exaggerated and emphatic repetition of a keyword that may become a theme for the talk. For instance, one might repeat separate in referring to libraries with a separate catalog for all the authors, separate catalog for all titles, and separate catalog for all subjects/topics in contrast to the clearer, simpler, and, by implication, superior, unified "dictionary" listing of one's local library. The humor rests in the tongue-incheek braggadocio, the body language, and the intonation, and the joke could be easily reversed, according to the local situation.

Puns should be avoided, along with allusions to the exotica of the youth scene.
Jokes that grow out of language learning or that build on shock at strange new customs usually go over well. Allusions are just as culture-bound, and, while the teacher/librarian might encounter the occasional student who will recognize the allusion, most will not. Allusions to things basically American or local simply will not work most of the time, but reference to recent international events (the Lebanese kidnappings, the Korean demonstrations, the Olympics), to internationally famous people, to sports (but not individual national athletes) are best. ${ }^{10}$ Both humor and allusions should be used to make dull materials more interesting, to help make the students feel at ease, to clarify rather than obscure. Since the composition of the international student body varies widely from college to college, trial and error is the best approach.

Analogies work far better with ESL students than either jokes or allusions. Because of their graphic nature, analogies can transcend language limitations and cultural differences and make language more interesting. They assume intelligence and are associated with adult thinking; therefore, they are perfect for bridging the gap and clarifying research concepts. For example, one might compare the card catalog to the catalog of a department store; both contain items that might be obtained once the listing system is understood and the items' particular numbers recorded. A comparison to a dictionary might help differentiate the single alphabet catalog from the divided one. The author-title-subject approach to locating the same book could be likened to using different routes to arrive at the same destination. In New Orleans, for example, to illustrate the multiple possibilities of a library search, we might ask the students if they have already been to the French Quarter, if they know how to get there, and by how many routes or modes of transportation they could reach their destination. A two-volume subject index could be likened to two bottles; if you fill one up, then you start on another. $A$ to $K$ may fill up one volume, so $L$ to $Z$ will fill up the next.

A citation or a call number could be com- 
pared to an address. If a student is looking for a friend and has only his or her first name, the task will be impossible. With the last name and a street name, he or she can come closer but will still have trouble. Only with the street number and the name can the student locate his or her friend. In like manner, part of a citation or call number is not very helpful; the whole number is the only guarantee of success in finding a book or article. ESL students relate well to such explanations, which put them at ease within the learning situation. Comparisons that are universal, obvious, and dramatic work best, and extending and exaggerating them heightens the students' pleasure, interest, and understanding.

\section{"Written and oral explanations are the least effective ways to communi- cate information about library use."}

Hands-on experience helps break down barriers. It also gives the librarian/teacher a better sense of what students are and are not understanding than does simple lecture or lecture with student response. Written and oral explanations are the least effective ways to communicate information about library use. What receives nods of understanding when described may prove perplexingly difficult when attempted. Therefore, an introductory session should consist of 20 to 40 percent explanation and 60 to 80 percent activity. Participation and immediate feedback must be encouraged by directing questions at individual students and drawing examples, whenever possible, from their backgrounds and experiences. Knowledge of the latter, of course, comes with the empathy that develops over time through continued contact with students from another culture. Activities to accompany a guided tour of the library might include looking up particular authors, books, or subjects in the card catalog, tracking down a subject in the Library of Congress Subject Headings, filling out a questionnaire that calls for specific biblio- graphic information from a citation. Students might also be asked to look up the same topic in a 1929, a 1950, and a 1980 Readers' Guide to see how listings can change, find a particular article on microfiche and microfilm, check out and return a book, fill out an interlibrary loan request, and so forth.

Clearly, such activities would consume far more time than is usually allotted to library tours, which leads to our most important suggestion for improving student library use: an arrangement between the intensive English program or the English department's ESL program and the library reference department or bibliographic instruction program for an integrated approach that would allow part of the English class time to be spent in an extended introduction. This would involve no more than ten students at a time (a larger number becomes unwieldy and some students may be excluded from discussions and activities) and would consist of a hands-on introduction by librarians with short exercises over six to eight class periods. To enhance its relevance to the students' work, the language teachers would make assignments that would require library support. For example, in the grammar class the section on noun clauses could be followed up with an assignment requiring students to find quotations on a subject and change them to indirect quotes; in the composition class these quotes could then be integrated into themes.

At Loyola the Intensive English program includes a research course at the advanced level that is integrated with the composition class and the library program. Thus students begin papers in composition, read about the card catalog and indexes in their research textbook, are introduced to library opportunities and strategies by the librarian (with the cooperation of the research course teacher), learn how to support arguments and cite sources in the research class, and track down potential sources in the library. The final product is a research paper that is judged by the composition teacher for skills in writing and rhetoric, and by the research teacher for the ability to find use- 